\title{
A reappraisal of the phylogenetic placement of the Aquilegia whole-genome duplication
}

\author{
Tao Shi ${ }^{1,2^{*}}$ (D) and Jinming Chen ${ }^{1,2^{*}}$
}

\author{
This comment refers to the article \\ available at https://doi.org/10.1186/ \\ s13059-020-02211-z. \\ * Correspondence: shitao323@ \\ wbgcas.cn; jmchen@wbgcas.cn \\ Please see the related Aköz and \\ Nordborg article: www.dx.doi.org/1 \\ 0.1186/s13059-019-1888-8. \\ ${ }^{1}$ Key Laboratory of Aquatic Botany \\ and Watershed Ecology, Wuhan \\ Botanical Garden, Chinese Academy \\ of Sciences, Wuhan 430074, China \\ Full list of author information is \\ available at the end of the article
}

\begin{abstract}
The accurate placement of an ancient whole-genome duplication (WGD) in relation to the lineage divergence is important. Here, we re-investigated the Aquilegia coerulea WGD and found it is more likely lineage-specific rather than shared by all eudicots.
\end{abstract}

Whole-genome duplications (WGDs) are frequent and common in plants, contributing to the evolutionary novelty and adaptation to extreme environments [1,2]. Aköz and Nordborg reported a common WGD in the ancestral eudicot: while this ancestral tetraploid is preserved in Aquilegia (a basal eudicot), the hexaploid in the ancestral core eudicot was formed by hybridization of this tetraploid and another diploid with a subsequent WGD [3]. Nevertheless, this is contradictory to the studies of Nelumbo nucifera $[4,5]$. Nelumbo, another basal eudicot, having a much closer relationship with core eudicots [6], shows a slower synteny loss and substitution rate than Aquilegia and core eudicots when aligned to outgroup species including Nymphaea colorata [7], rice, and Brachypodium distachyon (Figs. 1b and 2e) [4], and thus, Nelumbo should preserve more of its traces. However, the Ks peak corresponding to the "shared WGD" is absent in Nelumbo, and only a lineage-specific WGD after the Nelumbo-Macadamia split was found [4] (Fig. 2a), which raises doubt about their hypothesis of the common tetraploid origin.

The authors' assertion that the Aquilegia WGD is shared by all eudicots is mainly based on clustering by gene order similarity or structural similarity within species genome and between species, which depends on synteny evolutionary rate. When the trait evolves with rate heterogeneity, the simple clustering by similarity can hardly reflect the true phylogeny. Therefore, the more rapid loss of intraspecific synteny in Aquilegia might cause homoplasy such that higher similarity in gene order of Aquilegia-Vitis than Aquilegia-Aquilegia can be observed (Fig. 1a). Indeed, Aquilegia-Aquilegia shows the most rapid decay of synteny with the smallest size and the fewest number of syntenic blocks, which is even smaller and fewer than older divergent pairs (Aquilegia-Ceratophyllum and

(c) The Author(s). 2020 Open Access This article is licensed under a Creative Commons Attribution 4.0 International License, which permits use, sharing, adaptation, distribution and reproduction in any medium or format, as long as you give appropriate credit to the original author(s) and the source, provide a link to the Creative Commons licence, and indicate if changes were made. The images or other third party material in this article are included in the article's Creative Commons licence, unless indicated otherwise in a credit line to the material. If material is not included in the article's Creative Commons licence and your intended use is not permitted by statutory regulation or exceeds the permitted use, you will need to obtain permission directly from the copyright holder. To view a copy of this licence, visit http://creativecommons.org/licenses/by/4.0/. The Creative Commons Public Domain Dedication waiver (http://creativecommons.org/publicdomain/zero/1.0/) applies to the data made available in this article, unless otherwise stated in a credit line to the data. 


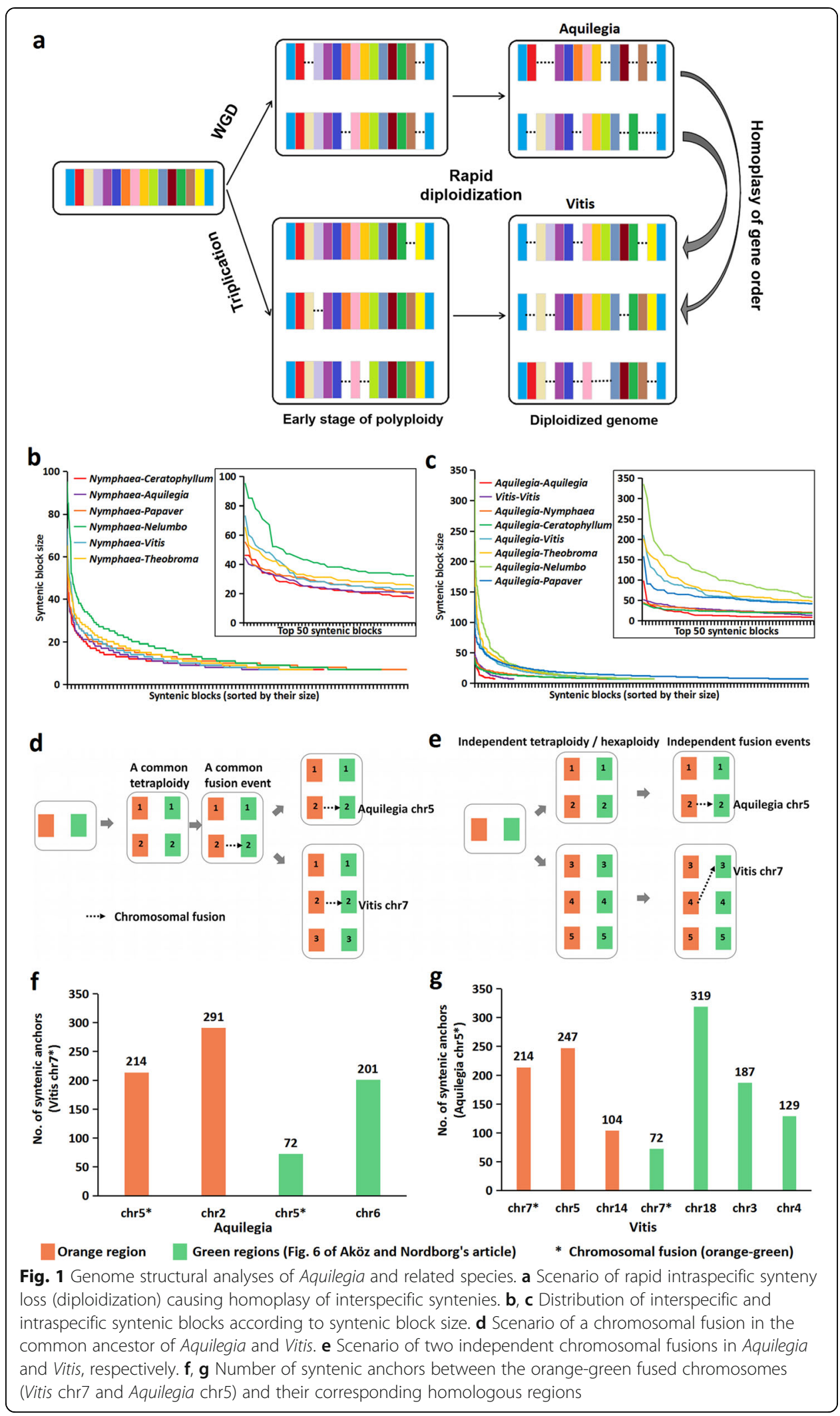




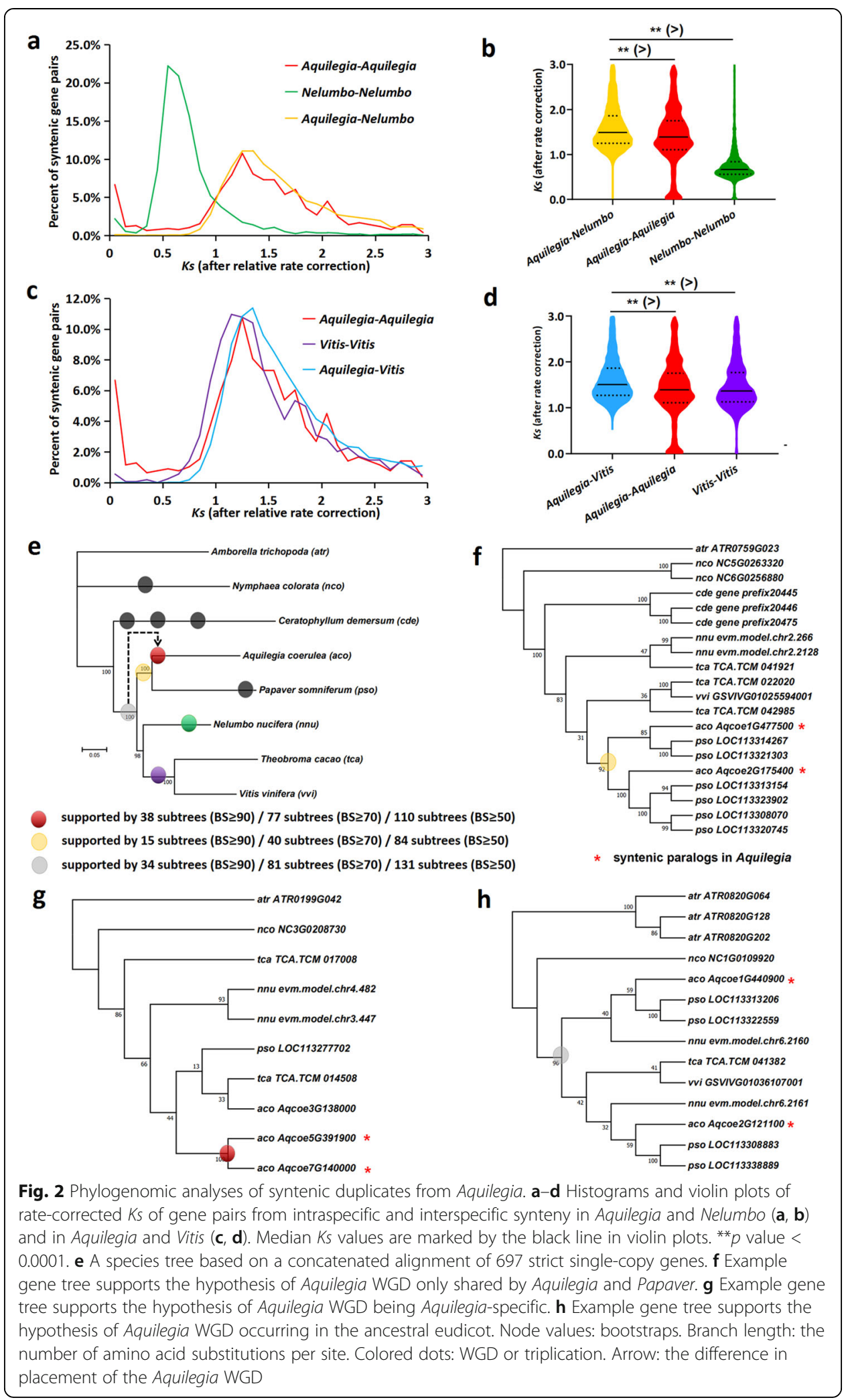


Aquilegia-Nymphaea) (Fig. 1c) [7]. Rapid convergent loss of the alternative copies, particularly housekeeping genes, by selection against redundancy after WGDs was found in angiosperms [8], and this is also congruent with more rapid syntenic gene loss that occurred soon after a WGD in teleost fish [9]. Therefore, their placement of a WGD simply by gene order similarity is flawed because of homoplasy caused by the heterogeneous rates of synteny loss. Meanwhile, the authors claimed that a fusion of ancestral eudicot chromosomes "green" and "orange" was observed in both Aquilegia chr5 and Vitis chr7, which is derived from a fusion in their tetraploid ancestor (Fig. 1d). Yet, they did not exclude an alternative possibility of two independent green-orange fusions in Aquilegia and Vitis, respectively (Fig. 1e). If their assumption is true, the fused green-orange chromosomes are expected to share closer homology (more syntenic anchors) to each other than the other green or orange regions. On the contrary, we found that the green and orange regions in the fused Vitis chr7 and Aquilegia chr6 share more anchors with non-fused green or orange regions (Fig. 1f, g). Therefore, the scenario of two independent chromosomal fusions is more likely.

Here, we showed that the Aquilegia WGD is more likely lineage-specific rather than common to all eudicots by two different phylogenomic approaches. (1) Ks values of syntenic paralogs and orthologs were measured to infer the sequential order of WGD and species divergence. Ks of each lineage were corrected using the relative rate (Aquilegia to Nelumbo to Vitis $=1: 0.750: 0.970$ ) based on Ks branch length ratios of 1425 single-copy ortholog groups [10]. For comparison, $K s>3$ were removed to prevent substitutional saturation [11]. The Ks distances of syntenic orthologs for both Aquilegia-Nelumbo and Aquilegia-Vitis are significantly longer than intraspecific paralogs in Aquilegia (Mann-Whitney $U$ test, both $p$ value $<0.0001$ ), suggesting this WGD exclusively occurred in Aquilegia (Fig. 2a-d). (2) To circumscribe Aquilegia syntenic duplicates in relation to the species divergence, 697 gene trees of ortholog groups from key taxa containing the Aquilegia syntenic paralogs were reconciled with the species tree using Notung2.9 (www.cs.cmu.edu/ durand/Notung) [12-14]. The species tree was constructed from 176 strict single-copy genes by OrthoFinder (www.stevekellylab.com/ software/orthofinder) and IQ-TREE (www.iqtree.org) (Fig. 2e). When we applied bootstrap thresholds of 90, 70, and 50, we found the hypothesis that Aquilegia syntenic duplications occurred after the divergence of Aquilegia and the ancestor of Nelumbo and core eudicots is supported by 53,117, and 194 subtrees, respectively (red and yellow dots in Fig $2 \mathrm{e}-\mathrm{g}$ ), whereas hypothesis that duplication occurred in the ancestral eudicot is supported by 34, 81, and 131 subtrees, respectively (gray dot in Fig. 2e, h). Due to the fact that Aquilegia WGD and Aquilegia-Papaver split are closely spaced in time, it is more difficult to resolve their sequential order. However, more subtrees support Aquilegia WGD being independent (red dot in Fig. 2e, g) than being shared by Aquilegia and Papaver (yellow dot in Fig. 2e, f), which is in line with a 2:2 syntenic relationship between Aquilegia and Papaver [15].

Acknowledgements

This work was supported by grants from the Strategic Priority Research Program of the Chinese Academy of Sciences (No. XDB31000000), the National Natural Science Foundation of China (Nos. 31570220, 31870208, and 31700197), Youth Innovation Promotion Association of the Chinese Academy of Sciences (No. 2019335), and Hubei Provincial Natural Science Foundation of China (No. 2019CFB275). 
Ethics approval and consent to participate

Not applicable.

\section{Consent for publication}

Not applicable.

\section{Competing interests}

The authors declare that they have no competing interests.

\section{Author details}

${ }^{1}$ Key Laboratory of Aquatic Botany and Watershed Ecology, Wuhan Botanical Garden, Chinese Academy of Sciences, Wuhan 430074, China. ${ }^{2}$ Center of Conservation Biology, Core Botanical Gardens, Chinese Academy of Sciences, Wuhan 430074, China.

Received: 22 May 2020 Accepted: 23 November 2020

Published online: 08 December 2020

\section{References}

1. Landis JB, Soltis DE, Li Z, Marx HE, Barker MS, Tank DC, Soltis PS. Impact of whole-genome duplication events on diversification rates in angiosperms. Am J Bot. 2018;105:348-63.

2. Van de Peer Y, Mizrachi E, Marchal K. The evolutionary significance of polyploidy. Nat Rev Genet. 2017;18:411-24.

3. Akoz G, Nordborg M. The Aquilegia genome reveals a hybrid origin of core eudicots. Genome Biol. 2019;20:256.

4. Shi T, Rahmani RS, Gugger PF, Wang M, Li H, Zhang Y, Li Z, Wang Q, Van de Peer Y, Marchal K, Chen J. Distinct expression and methylation patterns for genes with different fates following a single whole-genome duplication in flowering plants. Mol Biol Evol. 2020;37:2394-2413.

5. Ming R, VanBuren R, Liu Y, Yang M, Han Y, Li LT, Zhang Q, Kim MJ, Schatz MC, Campbell M, et al. Genome of the longliving sacred lotus (Nelumbo nucifera Gaertn.). Genome Biol. 2013;14:R41.

6. One Thousand Plant Transcriptomes I. One thousand plant transcriptomes and the phylogenomics of green plants. Nature. 2019:574:679-85.

7. Zhang L, Chen F, Zhang X, Li Z, Zhao Y, Lohaus R, Chang X, Dong W, Ho SYW, Liu X, et al. The water lily genome and the early evolution of flowering plants. Nature. 2020;577:79-84.

8. De Smet R, Adams KL, Vandepoele K, Van Montagu MC, Maere S, Van de Peer Y. Convergent gene loss following gene and genome duplications creates single-copy families in flowering plants. Proc Natl Acad Sci U S A. 2013;1 10:2898-903.

9. Inoue J, Sato Y, Sinclair R, Tsukamoto K, Nishida M. Rapid genome reshaping by multiple-gene loss after whole-genome duplication in teleost fish suggested by mathematical modeling. Proc Natl Acad Sci U S A. 2015;112:14918-23.

10. Shi T, Huang H, Barker MS. Ancient genome duplications during the evolution of kiwifruit (Actinidia) and related Ericales. Ann Bot. 2010;106:497-504.

11. Tiley GP, Barker MS, Burleigh JG. Assessing the performance of Ks plots for detecting ancient whole genome duplications. Genome Biol Evol. 2018;10:2882-98.

12. Argout X, Salse J, Aury JM, Guiltinan MJ, Droc G, Gouzy J, Allegre M, Chaparro C, Legavre T, Maximova SN, et al. The genome of Theobroma cacao. Nat Genet. 2011:43:101-8.

13. Yang $Y$, Sun $P, L v L$, Wang D, Ru D, Li Y, Ma T, Zhang L, Shen $X$, Meng F, et al. Prickly waterlily and rigid hornwort genomes shed light on early angiosperm evolution. Nat Plants. 2020;6:215-22.

14. Jaillon O, Aury JM, Noel B, Policriti A, Clepet C, Casagrande A, Choisne N, Aubourg S, Vitulo N, Jubin C, et al. The grapevine genome sequence suggests ancestral hexaploidization in major angiosperm phyla. Nature. 2007:449:463-7.

15. Guo L, Winzer T, Yang X, Li Y, Ning Z, He Z, Teodor R, Lu Y, Bowser TA, Graham IA, Ye K. The opium poppy genome and morphinan production. Science. 2018;362:343-7.

\section{Publisher's Note}

Springer Nature remains neutral with regard to jurisdictional claims in published maps and institutional affiliations.

Ready to submit your research? Choose BMC and benefit from:
- fast, convenient online submission
- thorough peer review by experienced researchers in your field
- rapid publication on acceptance
- support for research data, including large and complex data types
- gold Open Access which fosters wider collaboration and increased citations
- maximum visibility for your research: over 100M website views per year
At BMC, research is always in progress.
Learn more biomedcentral.com/submissions

